\section{Original Research}

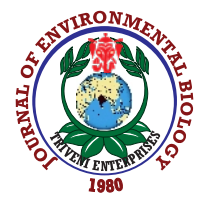

DOI : http://doi.org/10.22438/jeb/41/2(SI)/JEB-19
Journal Home page : www.jeb.co.in $\star$ E-mail : editor@jeb.co.in Journal of Environmental Biology

p-ISSN: 0254-8704 e-ISSN: 2394-0379 CODEN: JEBIDP

\title{
Control of soil erosion measures on mountain slopes
}

\author{
D. Kereselidze', L. Matchavariani ${ }^{2 *}$, V. Trapaidze', G. Bregvadze', G. Gaprindashvili ${ }^{3,4}$ and I. Megrelidze ${ }^{1,5}$ \\ 'Department of Hydrology, Oceanology and Meteorology, Faculty of Exact \& Natural Sciences, Tbilisi State University, Tbilisi - 0179, Georgia \\ ${ }^{2}$ Department of Soil Geography, Faculty of Exact \& Natural Sciences, Tbilisi State University, Tbilisi - 0179,Georgia \\ ${ }^{3}$ Department of Geology, National Environmental Agency, Tbilisi - 0112, Georgia \\ ${ }^{4}$ Department of Geomorphology, Vakhushti Bagrationi Institute of Geography, Tbilisi - 0177, Georgia \\ ${ }^{5}$ Department of Hydrometeorology, National Environmental Agency, Tbilisi - 0112, Georgia \\ *Corresponding Author Email : lia.matchavariani@tsu.ge
}

Paper received: 09.04.2019

Revised received: 02.10 .2019

Accepted: 08.12.2019

\section{Abstract}

Aim: Study of erosion processes caused by water and elaboration of the sophisticated methods, territorial zoning and creating of maps of sensitive areas using the GIS technologies, as well as quantitative assessment of the condition of the oil and gas pipelines corridors passing through Georgia and assessment of risks of dangerous and unfavorable situations.

Methodology: The research methodology is based on processes of the slope's flow motion. To represent this process, the equation of continuity of water flow was used, in which an important parameter is the velocity of water filtration in the soil. Filtration velocity depends on the intensity of rain and slope inclination. In addition, using Chézy-Manning formula, the depth of slope flow and volume of eroded soil was calculated.

Results: The study covers research of erosion by water on mountain sides and the engineering-ecological measures for its control, as well as the mitigation measures of the anticipated risks. Study results have great importance from the scientific as well as from the engineering and ecological point of view.

Interpretation: The method to calculate erosion intensity was developed, that allows realizing agrotechnical, hydrotechnical and phyto-melioration measures. The amount of eroded soils in different regions of Georgia was calculated. The ways of reducing filtration currents were studied, which will increase the safety of mountain slopes and reduce the negative effect of water erosion processes.

Key words: Filtration, Mountain slope, Rain intensity, Soil erosion

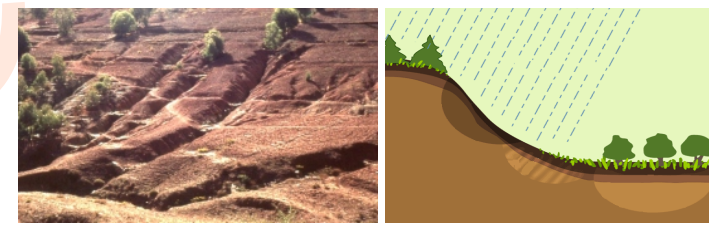

Slope inclination $3^{\circ}-5^{\circ}-7^{\circ}-10^{\circ}-15^{\circ}$

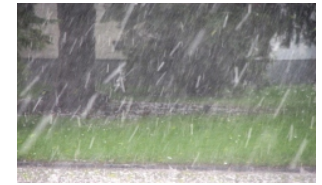

Rain Duration

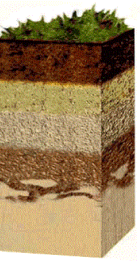

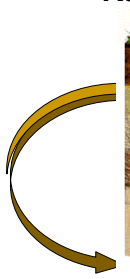

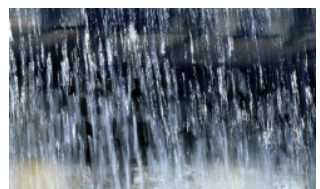

Rain Intensity

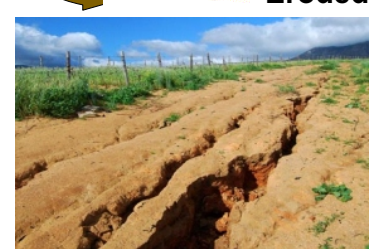

Filtration

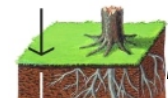

Coefficient

Eroded soils

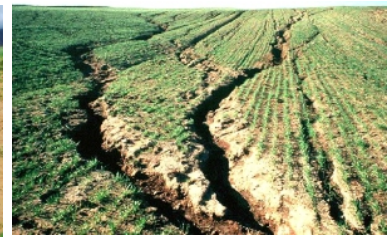

How to cite : Kereselidze, D., L. Matchavariani, V. Trapaidze, G. Bregvadze, G. Gaprindashvili and I. Megrelidze: Control of soil erosion measures on mountain slopes. J. Environ. Biol., 41, 405-412 (2020). 


\section{Introduction}

Soil erosion has become a global problem and more pronounced in the hills. It is more affected by the sparse vegetation (Bäumler, 2015; Bargali et al., 1993a\&b) and steep slopes governed by sub-surface flow where fine soil particles (silt and clay) get eroded with water and deposited in the foot hills (Bargali, 1996; Bargali et al., 2018) reduces the nutrient availability in the soil thus adversally affect the agricultural production in the hill region particularly (Bargali et al., 2019). Water erosion inflicts a great damage to the economy, particularly agriculture. It contributes to the loss of large areas of topsoil cover, pollution of water courses and water bodies and their filling with talus material, and deterioration of hydrological regimes of grounds. Water erosion makes the agricultural plots of field useless. Particularly, mountain regionsprovide favorable conditions for water erosion. The mountainous relief of Georgia, its complex geological and geomorphological conditions support the development of all kinds of erosive processes, with water erosion being most important. Despite the fact that much has been done in the study and prognosis of water erosion processes, the issue cannot be considered as resolved to the desired level. Even the results of verification of the best works accomplished so far at times show significant deviations from the reality. Researches on controlling erosion have been carried out for last seasonal decades in different regions of the world (Hudson, 1957; Meyer et al., 1975; Kirkby and Morgan, 1980; Flanagan and Nearing et al., 1995; Hairsine et al., 1999; Huang et al., 2001; Efe et al., 2008; Sharda et al., 2013). Problems of soil erosion control measures, particularly on mountain slopes, as well as mathematical calculation and modeling have been previously studied (Foster and Meyer, 1975; De Roo et al., 1996; Bryan, 2000; Morgan and Quinton, 2001; Heilig, et al., 2001; Presbitero et al., 2005; Boardman, 2006; Hacisalihoglu, 2007; Sander et al., 2009; Heng, et. al., 2009; Sandera et al., 2011).

The intensity and frequency of atmospheric precipitations have changed following global climate change, and surface runoff has been activated with multiple-factor, nature of cause and expected threats,. All these have made the water erosion processes on mountain slopes even more problematic. The scientists and practitioners should solve the problem by providing accurate forecasts, developing reliable and comprehensive methods and perfecting the anti-erosion structures. with regard to the ecological stability, among other anti-erosion measures, provision of special embankments is particularly important. The main goal of such embankments is to reduce filtration of surface water currents formed in the embankment body. The strategy of problem to protect land resources against water erosion is based on the accuracy of forecasting erosion processes at different stages, which in turn implies determining rain intensity and filtration currents for different gradients.

The methods of numerical prediction of erosive processes are based on the integral characteristics of soil resistance and non-scouring velocities of surface flow. As the latter exceed the critical values, the erosion starts. Despite a number of studies conducted to identify the said characteristics, there is no method, which considers the factors, which influence the final outcome. Importance of these factors is the impact of filtration on the surface flow. Consequently, the aim of the present paper was to consider the impact of filtration in the calculations of critical non-scouring velocities of surface currents.

\section{Materials and Methods}

The atmospheric precipitations on the territory of Georgia varies highly. The south-eastern coastline of the Black Sea receives great amount of atmospheric precipitations, while the south-eastern part of Georgia receives least. A part of the atmospheric precipitation is used for soil humidification, infiltration and evaporation, while the rest forms surface flow, which, during intense rains, cause soil erosion. In this respect, downpours are much hazardous.

During warm period of the year, frequent short-term precipitations do not form a surface flow. They are rather totally absorbed by the soil. However, when the upper layer of soil is saturated with moisture, long non-intense rains form a surface flow and soil erosion begins (Kereselidze et al., 2015).

Of the relief characteristics influencing the intensity of water erosion, the slope length and exposition, gradient and microrelief are notable. The length of slope has greatest impact on water erosion, because as the length increases, the water mass flowing down the slope increases and the flow velocity and energy increases too. Therefore, as the slope length increases, the risk of erosion processes get more intense and as well increases.

Together with the slope length, a strong impact on the erosion processes is exerted by surface gradient. The greater the gradient, the more favorable are the conditions for erosion. The studies have shown that a critical surface gradient is $3^{\circ}$ when the washout of soil particles starts for Georgia (Kereselidze et al., 2013). At this point, we should note that this does not mean that no soil erosion occurs with lesser gradients.

Alongside with the slope length and gradient, soil configuration plays a great role. A slope profile may be plane, convex or concave. In case of rectilinear profile, the erosion processes develop in the lower part of the slope; over the convex profile slopes, the erosion processes are more intense than over the concave profile slopes. By considering filtration over the mountain slopes, the main reason for intensified erosion processes is increased by bottom velocities of slope current. To illustrate this process, the formula of erosion process was used (Mirtskhulava, 2000): 


$$
W=\int_{0}^{L} \alpha w d\left(\frac{U_{\Delta}^{2}}{U_{\Delta H}}-1\right) d x
$$

where, $W$ is the volume of eroded soil; $w$ is like mean frequency of pulsating velocities; $d$ is the diameter of ground aggregates; $\alpha$ is the coefficient of proportionality; $U_{\Delta}$ is the actual water bottom velocity; and $U_{\Delta H}$ is the admissible (non-scouring/safe) bottom velocities.

The continuity equation of water current motion over the slopes of a mountain with a unit width is as follows:

$$
\frac{d Q}{d x}=Y-V_{0}
$$

where, $Q$ is the water discharge of slope runoff; $Y$ is the intensity of atmospheric precipitations (rain) and $V_{0}$ is the current filtration velocity through the soil.

$Q, Y$ and $V_{0}$ are the mean values during the fallen rain. It means that the rain intensity and rate of filtration does not change along the slope length. As for watershed, the slope runoff flow was zero it. Therefore, integration of eq. 2 gave the following expression:

$$
Q=\left(Y-V_{0}\right) x
$$

Using Chez-Manning formula (Larry, 2005), from Eq. 3, we get:

$$
h=\left[\frac{n\left(Y-V_{0}\right) x}{\sqrt{i}}\right]^{\frac{3}{5}} \cdot x^{\frac{3}{5}}
$$

where, $h$ is the depth of a slope current; $n$ is the resistance coefficient, and $i$ is the slope gradient.

Considering Eq. 4, Eq. 1 will be as follows:

$$
q=1.1 \cdot 10^{-6} \cdot w d\left[\frac{i^{0.7} \cdot \Delta^{\frac{1}{3}}(Y-V 0)^{0.6}}{n^{\frac{1}{5}} \cdot U_{\Delta H}^{2}} \cdot x^{0.6}-1\right]
$$

In the given case, $q$ is the aggregate volume of ground particles torn away by the action of water current.

Making Eq. 5 more suitable for calculations. Using ChezManning formula, let us write down the bottom velocity of the slope current as follows:

$$
U_{\Delta}=\frac{\sqrt{i} \cdot \Delta^{\frac{1}{6}}}{n} \cdot h^{\frac{1}{2}}
$$

$$
\begin{aligned}
& x=\frac{n\left(Y-V_{0}\right)}{\sqrt{i}} \cdot h^{\frac{5}{3}} \\
& d x=\frac{5 n\left(Y-V_{0}\right)}{\sqrt{i}} \cdot h^{\frac{2}{3}} \cdot d h
\end{aligned}
$$

Considering Eq. 8, Eq. 1 will be:

$$
q=1.1 w d\left[\frac{h}{h_{d}}-1\right]
$$

Where, $h_{d}$ is the admissible depth of the slope current and is equal to:

$$
h_{d}=\frac{n^{2} \cdot U_{\Delta d}^{2}}{i \cdot \Delta^{\frac{1}{3}}}
$$

By integrating Eq. 9 against $d x$ axis, from $x_{0}$ to $x$ and following simple transformations, we get:

$$
T \int_{x 0}^{x} d q x=\frac{5.5 \cdot 10^{-6} T w d \sqrt{ } i}{8_{n}\left(Y-V_{0}\right)} \cdot \frac{h^{\frac{8}{3}}-h_{d}^{\frac{8}{3}}}{h_{d}}-1.1 \cdot 10^{-6}{ }_{w d}\left(x-x_{0}\right) T
$$

Using Eq. 11, while calculating erosion intensity, depth $h$ is calculated with Eq. 4 and the admissible depth $\left(h_{d}\right)$ is calculated by Eq. 10 .

During the experiments or field surveys, they calculate runoff coefficient $\sigma_{\Delta}$ is calculated, which is related to the rain intensity and filtration velocity

$$
Y-V 0=\sigma_{\Delta} \cdot Y
$$

Consequently, the average filtration velocity can be determined by following equation:

$$
\mathrm{V} 0=\mathrm{Y}\left(1-\sigma_{\Delta}\right)
$$

\section{Results and Discussion}

Three million hectares of agricultural land over the mountain slopes in Georgia are eroded and potentially damaged due to water erosion (Table 1).

Using the calculation plan and Eq. 5 and 11 proposed by us, the volume of eroded soils in different regions of Georgia was calculated over the slopes with $3^{\circ}, 5^{\circ}, 7^{\circ}, 10^{\circ}$ and $15^{\circ}$ inclination (Fig. 1). The values of other parameters necessary for calculations are as follows: $n=0.025 ; \sigma_{Q}=0.1 ; U_{\Delta d}=0.1 \mathrm{~m} \mathrm{sec}^{-1}$.

Eight regions were selected, $4+4$ in West and East Georgia. The values of rain duration and intensity were taken from hydrometeorological data. The results are given in Table 2 and 3.

From the results, we get almost same picture for whole

From Eq. 4, we get: 
Table 1 : Distribution of agricultural field plots in Georgia according to gradients

\begin{tabular}{|c|c|c|c|c|c|c|c|}
\hline & \multirow{2}{*}{$\begin{array}{l}\text { Plots of field } \\
\text { (thous. ha) }\end{array}$} & \multicolumn{3}{|c|}{ Including areas with different gradients (degree) } & \multicolumn{2}{|c|}{ Eroded areas } & \multirow[b]{2}{*}{$\%$} \\
\hline & & $2-5$ & $5-10$ & $10-15$ & $<15$ & ha & \\
\hline East Georgia & 492.6 & 121.9 & 40.2 & 38.5 & 10.4 & 211 & 42.8 \\
\hline West Georgia & 456.0 & 35.0 & 13.3 & 13.3 & 5.6 & 79.2 & 50.0 \\
\hline
\end{tabular}
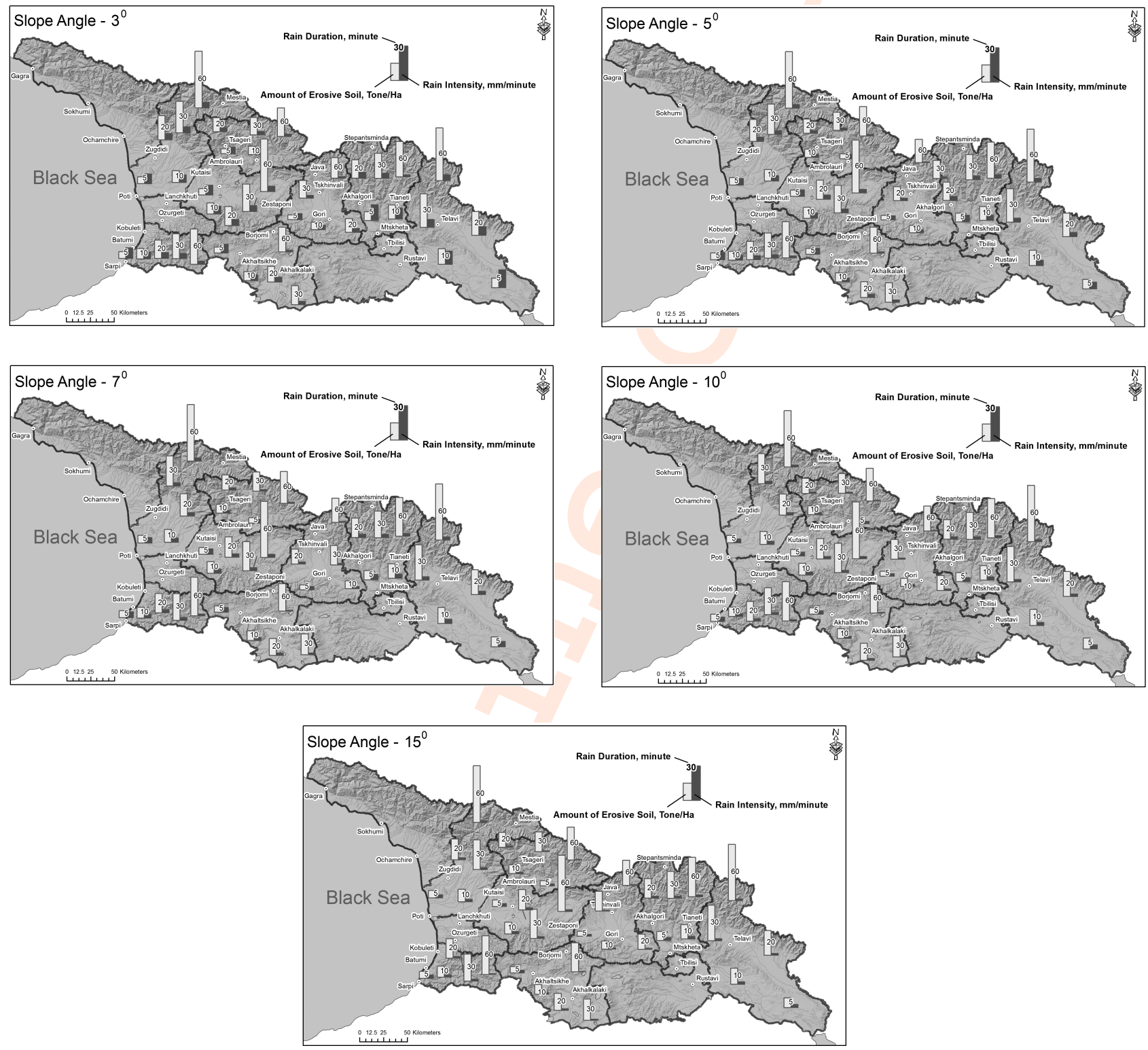

Fig. 1 : Erosive soils in different regions of Georgia.

Georgia - as inclination and rain duration and intensity increases, the filtration coefficient decreases and the erosion intensity increases. Rain intensity was less in Shida Kartli and SamtskheJavakheti regions. Therefore, despite the rain duration, erosion intensity was relatively less. High values of erosion intensity are characteristic to high-mountainous Zemo Imereti, Racha and ZemoAchara regions.

Erosion intensity for slopes with inclination of 3 to 5 degrees may be considered as average: $5-7 \mathrm{tha}^{-1}$; as high: $8-15 \mathrm{t}$ 
Table 2: Volume of eroded soils in West Georgia

\begin{tabular}{|c|c|c|c|c|c|c|c|c|c|c|c|c|c|}
\hline \multirow[t]{2}{*}{$i$} & \multirow[t]{2}{*}{$T$} & \multicolumn{3}{|c|}{ Imereti } & \multicolumn{3}{|c|}{ Racha } & \multicolumn{3}{|c|}{ Samegrelo } & \multicolumn{3}{|c|}{ Adjara } \\
\hline & & $W$ & $Y$ & $K$ & $w$ & $Y$ & $K$ & $W$ & $Y$ & $K$ & $w$ & $Y$ & $K$ \\
\hline \multirow[t]{5}{*}{$3^{\circ}(0.05)$} & 5 & 1.64 & 2.5 & 0.00090 & 1.27 & 1.7 & 0.00060 & 1.75 & 2.5 & 0.00095 & 1.73 & 2.7 & 0.00097 \\
\hline & 10 & 2.83 & 2.0 & 0.00071 & 2.11 & 1.3 & 0.00047 & 2.98 & 2.0 & 0.00083 & 2.64 & 1.8 & 0.00065 \\
\hline & 20 & 4.87 & 1.6 & 0.00058 & 3.51 & 1.0 & 0.00036 & 6.12 & 1.6 & 0.00062 & 4.66 & 1.5 & 0.00054 \\
\hline & 30 & 6.98 & 1.5 & 0.00054 & 4.44 & 0.8 & 0.00030 & 7.98 & 1.5 & 0.00051 & 6.33 & 1.3 & 0.00047 \\
\hline & 60 & 13.32 & 1.4 & 0.00049 & 7.21 & 0.6 & 0.00021 & 14.35 & 1.4 & 0.00047 & 8.95 & 0.8 & 0.00028 \\
\hline \multirow[t]{5}{*}{$5^{\circ}(0.09)$} & 5 & 2.42 & 2.5 & 0.00067 & 1.89 & 1.7 & 0.00045 & 2.84 & 2.5 & 0.00087 & 2.54 & 2.7 & 0.00072 \\
\hline & 10 & 4.19 & 2.0 & 0.00053 & 3.16 & 1.3 & 0.00035 & 4.37 & 2.0 & 0.00063 & 3.32 & 1.8 & 0.00048 \\
\hline & 20 & 7.25 & 1.6 & 0.00043 & 5.30 & 1.0 & 0.00027 & 8.25 & 1.6 & 0.00053 & 6.95 & 1.5 & 0.00040 \\
\hline & 30 & 10.42 & 1.5 & 0.00040 & 6.83 & 0.8 & 0.00021 & 11.41 & 1.5 & 0.00050 & 9.48 & 1.3 & 0.00035 \\
\hline & 60 & 19.92 & 1.4 & 0.00037 & 11.17 & 0.6 & 0.00016 & 21.32 & 1.4 & 0.00039 & 13.66 & 0.8 & 0.00021 \\
\hline \multirow[t]{5}{*}{$7^{\circ}(0.12)$} & 5 & 3.11 & 2.5 & 0.00060 & 2.43 & 1.7 & 0.00039 & 3.51 & 2.5 & 0.00067 & 3.26 & 2.7 & 0.00063 \\
\hline & 10 & 5.40 & 2.0 & 0.00043 & 4.09 & 1.3 & 0.00030 & 5.94 & 2.0 & 0.00052 & 5.05 & 1.8 & 0.00042 \\
\hline & 20 & 9.36 & 1.6 & 0.00038 & 6.89 & 1.0 & 0.00023 & 10.26 & 1.6 & 0.00041 & 8.98 & 1.5 & 0.00035 \\
\hline & 30 & 13.46 & 1.5 & 0.00035 & 8.91 & 0.8 & 0.00017 & 13.86 & 1.5 & 0.00038 & 12.27 & 1.3 & 0.00030 \\
\hline & 60 & 25.75 & 1.4 & 0.00032 & 14.68 & 0.6 & 0.00013 & 26.01 & 1.4 & 0.00032 & 17.82 & 0.8 & 0.00018 \\
\hline \multirow[t]{5}{*}{$10^{\circ}(0.19)$} & 5 & 4.33 & 2.5 & 0.00046 & 3.49 & 1.7 & 0.00031 & 4.73 & 2.5 & 0.00056 & 4.54 & 2.7 & 0.00049 \\
\hline & 10 & 7.53 & 2.0 & 0.00036 & 5.74 & 1.3 & 0.00024 & 8.21 & 2.0 & 0.00046 & 6.05 & 1.8 & 0.00033 \\
\hline & 20 & 13.09 & 1.6 & 0.00030 & 9.71 & 1.0 & 0.00019 & 13.49 & 1.6 & 0.00038 & 12.57 & 1.5 & 0.00027 \\
\hline & 30 & 18.85 & 1.5 & 0.00027 & 12.6 & 0.8 & 0.00014 & 19.27 & 1.5 & 0.00031 & 17.22 & 1.3 & 0.00024 \\
\hline & 60 & 36.10 & 1.4 & 0.00025 & 120.90 & 0.6 & 0.00011 & 36.10 & 1.4 & 0.00025 & 25.22 & 0.8 & 0.00015 \\
\hline \multirow[t]{5}{*}{$15^{\circ}(0.26)$} & 5 & 5.42 & 2.5 & 0.00039 & 4.27 & 1.7 & 0.00026 & 6.12 & 2.5 & 0.00041 & 5.69 & 2.7 & 0.00042 \\
\hline & 10 & 9.44 & 2.0 & 0.00031 & 7.21 & 1.3 & 0.00021 & 10.02 & 2.0 & 0.00036 & 8.84 & 1.8 & 0.00028 \\
\hline & 20 & 16.43 & 1.6 & 0.00025 & 12.23 & 1.0 & 0.00016 & 16.83 & 1.6 & 0.00029 & 15.73 & 1.5 & 0.00023 \\
\hline & 30 & 23.68 & 1.5 & 0.00023 & 15.91 & 0.8 & 0.00012 & 24.01 & 1.5 & 0.00025 & 21.64 & 1.3 & 0.00022 \\
\hline & 60 & 45.35 & 1.4 & 0.00021 & 26.46 & 0.6 & 0.00009 & 45.75 & 1.4 & 0.00021 & 31.33 & 0.8 & 0.00010 \\
\hline
\end{tabular}

I = Slope angle; $\mathrm{T}=$ Rain Duration, minute; $\mathrm{W}=$ Amount of Erosive Soil, Tone/Ha; $\mathrm{Y}=$ Rain Intensity, $\mathrm{mm} /$ minute; $\mathrm{K}=$ Filtration Coefficient

Table 3: Volume of eroded soils in East Georgia

\begin{tabular}{|c|c|c|c|c|c|c|c|c|c|c|c|c|c|}
\hline \multirow[t]{2}{*}{$i$} & \multirow[t]{2}{*}{$T$} & \multicolumn{3}{|c|}{ Kakheti } & \multicolumn{3}{|c|}{ Mtskheta-Mtianeti } & \multicolumn{3}{|c|}{ Shida Kartli } & \multicolumn{3}{|c|}{ Samtskhe-Javakheti } \\
\hline & & $W$ & $Y$ & $K$ & $w$ & $Y$ & $K$ & $w$ & $Y$ & $K$ & $W$ & $Y$ & $K$ \\
\hline \multirow[t]{5}{*}{$3^{\circ}(0.05)$} & 5 & 2.41 & 4.5 & 0.00161 & 2.23 & 4.0 & 0.00144 & 1.16 & 1.5 & 0.00054 & 1.51 & 2.2 & 0.00079 \\
\hline & 10 & 3.94 & 3.3 & 0.00118 & 3.54 & 2.8 & 0.00101 & 1.88 & 1.1 & 0.00039 & 2.33 & 1.5 & 0.00054 \\
\hline & 20 & 6.03 & 2.2 & 0.00079 & 4.66 & 1.5 & 0.00054 & 3.51 & 1.0 & 0.00036 & 3.99 & 1.2 & 0.00043 \\
\hline & 30 & 8.49 & 2.0 & 0.00071 & 6.33 & 1.3 & 0.00047 & 4.47 & 0.7 & 0.00028 & 4.87 & 0.9 & 0.00032 \\
\hline & 60 & 13.32 & 1.4 & 0.00049 & 8.95 & 0.8 & 0.00028 & 5.23 & 0.4 & 0.00015 & 6.26 & 0.5 & 0.00017 \\
\hline \multirow[t]{5}{*}{$5^{\circ}(0.09)$} & 5 & 3.52 & 4.5 & 0.00112 & 3.27 & 4.0 & 0.00107 & 1.74 & 1.5 & 0.00040 & 2.23 & 2.2 & 0.00059 \\
\hline & 10 & 5.75 & 3.3 & 0.00088 & 5.21 & 2.8 & 0.00075 & 2.83 & 1.1 & 0.00029 & 3.47 & 1.5 & 0.00040 \\
\hline & 20 & 8.92 & 2.2 & 0.00059 & 6.95 & 1.5 & 0.00054 & 5.30 & 1.0 & 0.00027 & 5.99 & 1.2 & 0.00032 \\
\hline & 30 & 12.58 & 2.0 & 0.00051 & 9.48 & 1.3 & 0.00047 & 6.83 & 0.7 & 0.00021 & 7.40 & 0.9 & 0.00024 \\
\hline & 60 & 19.92 & 1.4 & 0.00037 & 13.66 & 0.8 & 0.00028 & 8.83 & 0.4 & 0.00011 & 9.81 & 0.5 & 0.00013 \\
\hline \multirow[t]{5}{*}{$7^{\circ}(0.12)$} & 5 & 4.50 & 4.5 & 0.00105 & 4.18 & 4.0 & 0.00094 & 2.24 & 1.5 & 0.00035 & 2.87 & 2.2 & 0.00051 \\
\hline & 10 & 7.41 & 3.3 & 0.00077 & 6.68 & 2.8 & 0.00066 & 3.67 & 1.1 & 0.00025 & 4.48 & 1.5 & 0.00035 \\
\hline & 20 & 11.47 & 2.2 & 0.00052 & 8.98 & 1.5 & 0.00035 & 6.89 & 1.0 & 0.00023 & 7.77 & 1.2 & 0.00032 \\
\hline & 30 & 16.19 & 2.0 & 0.00046 & 12.27 & 1.3 & 0.00031 & 8.91 & 0.7 & 0.00018 & 9.64 & 0.9 & 0.00021 \\
\hline & 60 & 25.75 & 1.4 & 0.00032 & 17.82 & 0.8 & 0.00018 & 11.07 & 0.4 & 0.00010 & 12.65 & 0.5 & 0.00011 \\
\hline
\end{tabular}

Cont... 


\begin{tabular}{llllllllllllll}
$10^{\circ}(0.19)$ & 5 & 6.93 & 4.5 & 0.00082 & 5.80 & 4.0 & 0.00074 & 3.14 & 1.5 & 0.00027 & 4.00 & 2.2 & 0.00041 \\
& 10 & 10.29 & 3.3 & 0.00060 & 9.30 & 2.8 & 0.00052 & 5.16 & 1.1 & 0.00020 & 6.28 & 1.5 & 0.00029 \\
& 20 & 15.99 & 2.2 & 0.00041 & 12.57 & 1.5 & 0.00024 & 9.71 & 1.0 & 0.00019 & 10.91 & 1.2 & 0.00022 \\
& 30 & 22.60 & 2.0 & 0.00036 & 17.22 & 1.3 & 0.00024 & 12.71 & 0.7 & 0.00015 & 13.61 & 0.9 & 0.00016 \\
& 60 & 36.10 & 1.4 & 0.00025 & 25.22 & 0.8 & 0.00015 & 15.94 & 0.4 & 0.00009 & 18.52 & 0.5 & 0.00009 \\
$15^{\circ}(0.26)$ & 5 & 7.79 & 4.5 & 0.00070 & 7.24 & 4.0 & 0.00063 & 3.95 & 1.5 & 0.00023 & 5.01 & 2.2 & 0.00035 \\
& 10 & 12.87 & 3.3 & 0.00052 & 11.63 & 2.8 & 0.00044 & 6.49 & 1.1 & 0.00016 & 7.89 & 1.5 & 0.00023 \\
& 20 & 20.04 & 2.2 & 0.00035 & 15.78 & 1.5 & 0.00023 & 12.23 & 1.0 & 0.00015 & 13.72 & 1.2 & 0.00018 \\
& 30 & 28.60 & 2.0 & 0.00031 & 21.64 & 1.3 & 0.00021 & 15.91 & 0.7 & 0.00011 & 17.15 & 0.9 & 0.00014 \\
& 60 & 45.35 & 1.4 & 0.00020 & 31.83 & 0.8 & 0.00012 & 20.30 & 0.4 & 0.00006 & 23.50 & 0.5 & 0.00007 \\
\hline
\end{tabular}

$\mathrm{I}=$ Slope angle; $\mathrm{T}=$ Rain Duration, minute; $\mathrm{W}=$ Amount of Erosive Soil, Tone $/ \mathrm{Ha} ; \mathrm{Y}=$ Rain Intensity, $\mathrm{mm} / \mathrm{minute} ; \mathrm{K}=$ Filtration Coefficient

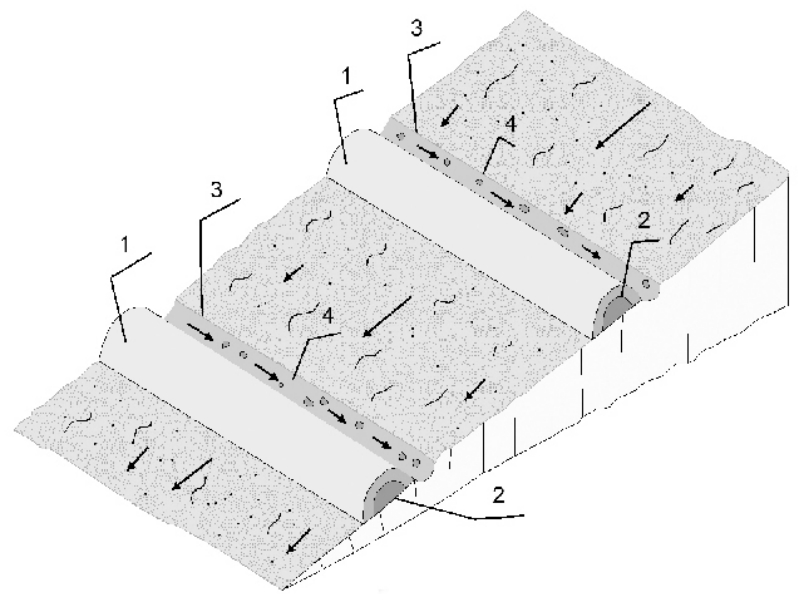

Fig. 2 : Anti-Erosive bunds (embankments) on the mountain slopes: (1) Soil-ground bund; (2) High-quality anti-filtration screen made with clay and loamy ground; (3) Water channel made with clay and loamy ground; and (4) Water channel faced with stone material.

ha ${ }^{-1}$ for slopes with the inclination of $7-10^{\circ}$; and as very high: over $15 \mathrm{t} \mathrm{ha}^{-1}$ for the slopes with the inclination of $15^{\circ}$. Besides, considering that the number of downpours will increase following climate change and following the mountainous relief of Georgia, most of the land plots are located over the slopes with inclination of $5-10^{\circ}$, it can be considered that the intensity of erosive processes is not high in the whole region of the country.

The given kind of study was conducted for the first time on the territory of Georgia by using the methodology proposed by us. In addition to the theoretical studies, numerous studies were conducted. It should be noted that the given kind of research were conducted for the under the leadership of Academician Tsotne Mirtskhulava (2000), but these studies did not envisage water filtration in soil. We tried to consider the role of the filtration coefficient, what specifies and makes investigation of erosion process realistic.

Using the calculation plan and Eq. 5 and 11, the volume of eroded soils in different regions of Georgia was calculated over the slopes with $3^{\circ}, 5^{\circ}, 7^{\circ}, 10^{\circ}$ and $15^{\circ}$ inclination. The results are given in the maps (Fig. 1). The values of other parameters necessary for calculations are as follows: $\mathrm{n}=0.025 ; Q \sigma=0.1$; ${ }_{d} U_{\Delta}=0.1 \mathrm{~m} \mathrm{sec}-1$.

Eight regions were selected, $4+4$ in West and East Georgia for the studies. Distribution of the agricultural field plots according to the gradients is given in the Table 1. Three million hectares of agricultural land over the mountain slopes in Georgia and potentially damaged due to water erosion (Table 1). The values of rain duration and intensity were taken from hydrometeorological data of Georgia. The results are given in Table 2 and 3. The geomorphological and climatic factors, types of soil, land use practices and level of development of agriculture at different hypsometric altitudes in the West Georgia (Imereti, Racha, Samegrelo and Ajara) are almost similar. As the rain duration and slope inclination increase, the values of erosion vary within quite a wide range and are 1.64-45.35 $\mathrm{t} \mathrm{ha}^{-1}$ in Zemo Imereti, 1.27-26.46 tha ${ }^{-1}$ in Racha, 1.73-31.33 tha ${ }^{-1}$ in Zemo Ajara and 1.75-45.75 $\mathrm{tha}^{-1}$ in Samegrelo and the value of the filtration coefficient decreases proportionally. As for East Georgia (Kakheti, Mtskheta-Mtianeti, Samtskhe-Javakheti and Shida Kartli) only Mtskheta-Mtianeti Region is outstanding with its peculiar land use practice, while the situation is nearly the same in other three Regions. The erosion values in these Regions are as follows: 2.41-45.35 tha ${ }^{-1}$ in Kakheti, 2.23-31.83 tha ${ }^{-1}$ in MtskhetaMtianeti, $1.16-20.30$ t ha $^{-1}$ in Shida Kartli and 1.51-23.50 tha ${ }^{-1}$ in Samtskhe-Javakheti.

Despite the diversity of the soil cover in humid subtropical region (Western Georgia), the intensity and duration of precipitation are crucial for the development of erosion processes. While in the eastern regions of Georgia, where soil diversity is relatively less, the result of erosion is mainly due to land use practices and the morphology of the area.

From the results, we get almost same picture for whole Georgia - as inclination and rain duration and intensity increases, the filtration coefficient decreases and the erosion intensity increases. Rain intensity was less in Shida Kartli and Samtskhe- 
Javakheti regions. Therefore, despite the rain duration, erosion intensity was relatively less. High values of erosion intensity are characteristic to high-mountainous Zemo Imereti, Racha and Zemo Achara regions.

Erosion intensity for slopes with inclination of 3 to 5 degrees may be considered as average: $5-7 t^{-1} a^{-1}$ as high: $8-15 t$ $\mathrm{ha}^{-1}$ for slopes with the inclination of $7-10^{\circ}$ and as very high: over $15 \mathrm{t} \mathrm{ha}^{-1}$ for the slopes with the inclination of $15^{\circ}$. Besides, considering that the number of downpours will increase following climate change and following the mountainous relief of Georgia, most of the land plots are located over the slopes with inclination of $5-10^{\circ}$, it can be considered that the intensity of erosive processes is nothigh in the whole region of the country.

If the intensity of atmospheric precipitations is little and the soil has great water permeability, the value of erosion may not increase as the slope inclination increases.

Water erosion control measures : Anti-erosion measures imply providing special embankments, which are built by compacting a high-quality fill and inserting a clay core in the embankment body at a depth greater than the ground washout depth. The embankments are covered with local ground, which give them a semi-circular or elliptic shape that ensures reduction of filtration of surface water current formed over the mountain slope in the embankment body thus, improving the reliability of ground embankment structures. Besides, with the purpose of a rapid transfer of surface water currents accumulated in the headrace of embankments, there is a water-conduit channel provided with clay and loamy soil, with its cross section faced with the local stone material. These channels accelerate the outflow of the surface water currents from the mountain slopes and reduce the filtration currents. This reduces water erosion processes over the mountain slopes. The geometry of embankments and distance between them, the size of anti-filtration screen and hydraulic parameters of faced water-conduit channel was calculated by considering the mountain slope gradient, geological properties of ground and rain intensity (Fig. 2).

For concerning soil resources, the formula used to calculate erosion intensity allowed realizing agrotechnical, hydrotechnical and phyto-melioration measures. Based on the design model, the amount of eroded soils in different regions of Georgia were calculated. Reduced filtration currents in the soil and ground embankments over the mountain slopes need to be considered as an innovative trend. Providing a fill by high-quality compaction with clay and loamy soil material in the embankment body will minimize the filtration of surface water currents and, consequently, reduce the risk of the embankment failure. A water-conduit channel provided in the headrace of the embankment accelerates the outflow of surface water currents from the mountain slopes and reduces filtration currents, which in turn increase the safety of mountain slopes and reduce the negative effect of water erosion processes.

\section{References}

Bäumler, R.: Soils. In: An introduction to the natural history, ecology and human environment in the Himalayas-A companion to the flora of Nepal (Eds.: G. Miehe, C. Pendry and R. Chaudhary). $1^{\text {st }}$ Edn., Edinburgh: The Royal Botanical Garden Edinburgh, pp. 125-134 (2015).

Bargali, K., Manral, V., Padalia, K., Bargali, S. S. and V. P. Upadhyay: Effect of vegetation type and season on microbial biomass carbon in Central Himalayan forest soils, India. Catena, 171, 125-135 (2018).

Bargali, S. S.: Weight loss and N release in decomposing wood litter in a eucalypt plantation age series. Soil Biol. Biochem., 28, 699-702 (1996).

Bargali, S. S., R. P. Singh and M. Joshi: Changes in soil characteristics in eucalypt plantations replacing natural broad - leaved forests. J. Veg. Sci., 4, 25-28 (1993a).

Bargali, S.S., S.P. Singh and R.P. Singh: Pattern of weight loss and nutrient release in decomposing leaf litter in an age series of eucalypt plantations. Soil Biol. Biochem., 25, 1731-1738 (1993).

Bargali, S.S., K. Padalia and K. Bargali: Effects of tree fostering on soil health and microbial biomass under different land use systems in Central Himalaya. Land Degrad. Develop., 30, 1984-1998 (2019).

Boardman, J.: Soil erosion science: Reflections on the limitations of current approaches. Catena, 68, 71-86 (2006).

Bryan, R.B.: Soil erodibility and processes of water erosion on hill slope. Geomorphology, 32, 385-415 (2000).

De Roo, A.P.J., C.G. Wesseling and C.J. Ritsema: LISEM: A single event physically-based hydrologic and soil erosion model for drainage basins: I. Theory, input and output. Hydrological Processes, 10, 1107-1117 (1996).

Efe, R., D. Ekinci and I. Cürebal: Erosion analysis of Fındıklı Creek catchment (North west of Turkey) using GIS based on RUSLE (3D) Method. Frese. Environ. Bull., 17, 568-576 (2008).

Flanagan, D.C. and M.A. Nearing: Water erosion prediction project: Hillslope profile and watershed documentation. NSERL Report No. 10, USDA-ARS National Soil Erosion Research Laboratory, West Lafayette, Indiana, USA(1995).

Foster, G.R. and L.D. Meyer: Mathematical simulation of upland erosion using fundamental erosion mechanics. In: Proceedings, sediment yield workshop., Report RS-S-40, 190 - 207, USDA Sedimentation Laboratory, Oxford Mississippi, USA(1975).

Hacisalihoglu, S.: Determination of soil erosion in a steep hill slope with different land-use types: A case study in Mertesdorf (Ruwertal/ Germany). J. Environ. Biol., 28, 433-438 (2007).

Hairsine, P.B., G.C. Sander, C.W. Rose, J.Y. Parlange, W.L. Hogarth, I. Lisle and M. Roukipow: Unsteady soil erosion due to rainfall impact : A model of sediment sorting on the hillslope. J. Hydrol., 220, 115128 (1999).

Heilig, A., D. DeBruyn, M.T. Walker, C.W. Rose, J.Y. Parlange, T.S. Steenhuis, G.C. Sander, P.B. Hairsine, W.L. Hogarth and L.P. Walker: Testing a mechanistic soil erosion model with a simple experiment. J. Hydrol., 244, 9-16 (2001).

Heng, B.C.P., G.C. Sander and C.F Scott: Modelling overland flow and soil erosion on nonuniform hillslopes: A finite volume scheme. Water Resour. Res., 45, W05423 (2009).

Huang, C., C.G. Odoux and S.C. Cayot: Hillslope topographic and 
hydrologic effects on overland flow and erosion. Catena, 46, $177-$ 188 (2001).

Hudson, N.W.: Erosion control research. Rhodesia Agr. J., 54, 297-323 (1957).

Kereselidze, D., L. Matchavariani, V. Trapaidze, L. Lagidze, D. Svanadze, G. Bregvadze and Z. Gulashvili: Quantitative assessment of permissible loads on Georgia's soil. American J. Environ. Protec., (Special Issue) Applied Ecology: Problems, Innovations, Vol. 4, 29-33 (2015).

Kereselidze, D.N., L. Machavariani., B.B. Kalandadze and V.Z. Trapaidze: Allowable soil erosion rates in Georgia. Eur. Soil Sci., 46, 438-446 (2013).

Larry, W. Mays: Water resources engineering. John Wiley and Sons, Inc., p. $842(2005)$

Kirkby, M.J. and R.P.C. Morgan (Eds.): Soil Erosion. Wiley, New York (1980).

Meyer, L.D., G.R. Foster and M.J.M. Römkens: Source of soil eroded by water from upland slopes (1975).
Mirtskhulava, Ts.: Water Rrosion of Soil. Tbilisi, Nauka, p. 420 (2000).

Morgan, R.P.C. and J.N. Quinton: Erosion modelling. In: Landscape Erosion and Erosion Modelling (Eds.: W.W. Doe and R.S. Harmon). Kluwer Academic Press, New York, USA, pp. 117-139 (2001).

Presbitero, A.L., C.W. Rose, B. Yu, C.A.A. Ciesiolka, K.J. Coughlan and $B$. Fentie: Investigation of soil erosion from bare steep slopes of the humid tropic Philippines. Earth Interactions, 9, (2005).

Sander, G.C., C.W. Rose, W.L. Hogarth, J.Y. Parlange and I.G Lisle: Mathematical Soil Erosion Modeling. In: Water Interactions with Energy, Environment, Food and Agriculture. Vol. II, @Encyclopedia of Life (2009).

Sandera, G.C., T. Zheng, P. Heng, Y. Zhongc and D.A. Barry: Sustainable soil and water resources: modelling soil erosion and its impact on the environment. 19th International Congress on Modelling and Simulation, Perth, Australia, pp. 45-56 (2011).

Sharda, V.N., D. Mandal and P.R. Ojasvi: Identification of soil erosion risk areas for conservation planning in different states of India. $\mathrm{J}$. Environ. Biol., 34, 219-226 (2013) 